\title{
Selectieve perceptie in het medisch vraaggesprek: het effect van diagnostische kennis op het waar- nemen van klachten in een consult
}

\author{
M.M.L. van den Hove, J. van Dalen, J-J. Rethans, E.H.B.M. Gronenschild, S. Roos
}

\section{Samenvatting}

Inleiding: Eerder onderzoek naar het onthouden van patiëntinformatie door artsen met verschillende niveaus van expertise laat tegenstrijdige resultaten zien. In dit onderzoek wordt nagegaan in hoeverre studenten uit verschillende studiejaren (met toenemende diagnostische kennis) klachten van een patiënt onthouden. De hypothesen hierbij zijn:

- Studenten met meer diagnostische kennis geven minder atypische klachten weer dan studenten uit lagere studiejaren.

- Studenten met meer diagnostische kennis geven vaker typische klachten weer bij een diagnose, ook als deze niet door de patiënt worden geuit.

Methode: Drie gesimuleerde consulten zijn opgenomen op video en bekeken door studenten uit de eerste vier jaren van de studie geneeskunde aan de Universiteit Maastricht (UM). Direct na elk consult werd hen gevraagd zoveel mogelijk klachten die ze gehoord hadden in te voeren in een computerprogramma, evenals de waarschijnlijke diagnose. De gerapporteerde klachten werden in vier verschillende categorieën (typisch of atypisch en genoemd of niet genoemd) ingedeeld. Verschillen in de invoer voor elke categorie tussen de vier jaargroepen werden getoetst met ANOVA.

Resultaten: Er werden geen significante verschillen gevonden in aantallen of aard van de onthouden klachten. Wel leken de ouderejaars bij twijfel vaker toch een (foute) diagnose in te vullen, wellicht door overschatting van hun kennis.

Conclusie: Toename van diagnostische expertise lijkt in de eerste vier studiejaren geen effect te hebben op het waarnemen en onthouden van klachten tijdens een consult. Verder onderzoek is nodig om gevolgen van toename in expertise in latere stadia van de opleiding op te sporen en de effecten van eventuele overschatting van diagnostische kennis vast te stellen. (Hove MML van den, Dalen J van, Rethans J-J, Gronenschild EHBM, Roos S. Selectieve perceptie in het medisch vraaggesprek: het effect van diagnostische kennis op het waarnemen van klachten in een consult. Tijdschrift voor Medisch Onderwijs 2004;23(3):133-142.)

\section{Inleiding}

Bijna zestig jaar geleden presenteerde de Groot zijn nu legendarische studie naar het geheugen van schaakgrootmeesters. Hierin toonde hij aan dat deze experts een veel betere herinnering of 'recall' hadden voor schaakposities dan leken, mits het zinvolle posities betrof. Opstellingen die niet realistisch waren voor het schaakspel, dus volkomen willekeurig geplaatste stukken, werden door experts en novices even slecht onthouden. ${ }^{1}$ Deze verschillen werden voor het eerst verklaard door Chase en Simon, die stelden dat de verwerking van informatie in grotere, betekenisvolle eenheden of 'chunks' de recall van de experts sterk verbeterde. ${ }^{2}$

Sinds deze studies is er binnen de cognitieve psychologie veel onderzoek gedaan naar de informatieverwerking en het geheugen van experts, op verschillende gebieden van expertise. Binnen de genees- 
kunde zijn deze onderzoeken zeer divers van opzet en ook de resultaten zijn minder eenduidig dan in andere vakgebieden. De oorspronkelijke resultaten van de schaakstudies werden door een aantal onderzoekers bevestigd, maar minstens evenveel studies vonden geen significante verschillen tussen novices en experts of zelfs tegengestelde resultaten.

Coughlin en Patel toonden aan dat de recall van huisartsen voor geschreven casus groter was dan die van tweedejaars medisch studenten, indien het tenminste kritieke informatie (voor een diagnose) in een logische patiëntenpresentatie betrof. Van niet-kritieke, random aangeboden informatie herinnerden artsen en studenten zich evenveel. ${ }^{3}$ Dit verschil in herinnering van typische en atypische informatie werd al eerder gevonden door Norman, die vier niveaus van expertise (studenten, beginnende en gevorderde arts-assistenten en specialisten) bij zijn onderzoek betrok en ook werkte met geschreven casus. ${ }^{4}$ Dezelfde auteur gebruikte later laboratoriumwaarden en vond daarbij geen significante verschillen tussen de expertiseniveaus. ${ }^{5}$

Een heel ander patroon van recall werd herhaaldelijk aangetoond door onder andere Schmidt en Boshuizen, namelijk het 'intermediate effect'. 6 Dit effect houdt in dat 'intermediates', personen die zich nog volop in het proces van expertiseontwikkeling bevinden (bijvoorbeeld arts-assistenten), betere resultaten laten zien op een geheugentest dan de echte experts. Een verklaring voor dit fenomeen ligt volgens de auteurs in de 'illness-script theorie', een model voor de representatie van (medische) kennis op verschillende levels van expertise. Volgens deze theorie is een belangrijke eigenschap van de kennisrepresentatie van experts 'encapsulation': het vermogen om vele gedetailleerde omschrijvingen onder een grotere noemer te laten samenvallen (bijvoorbeeld: een student onthoudt van een patiënt de symptomen 'pijn op de borst, angst, zweten, kortademig', een ervaren arts vat dit samen als 'angina pectoris'). ${ }^{7-8}$ Onder tijdsrestricties blijkt het intermediate effect echter te verdwijnen: de expert wordt dan weer superieur. ${ }^{7}$

Een mogelijke verklaring voor de wisselende resultaten uit deze studies is dat men gebruik maakte van papieren casus. Uit de literatuur is namelijk de term 'encoding specificity' bekend, waarmee bedoeld wordt dat recall beter is als de omstandigheden tijdens de leer- en de reproduceerfase zoveel mogelijk gelijk zijn. ${ }^{9}$

Veel aandacht is ook geschonken aan 'foute' herinneringen: recall van items die niet in de oorspronkelijke informatie voorkwamen. Vanuit de illness-script theorie werd het fenomeen 'script-instantiation' geïntroduceerd: het aanvullen van informatie die ontbreekt bij een specifieke casus en er volgens het geactiveerde script wel bij hoort. ${ }^{10}$ Aangezien experts de meest complete scripts gebruiken, werd verwacht dat zij dan ook de meeste informatie zouden 'verzinnen'. Hoewel resultaten die deze verwachting bevestigen gevonden zijn, ${ }^{11}$ is er ook veel onderzoek uitgevoerd dat erop wijst dat juist novices meer informatie (foutief) aanvullen, 12 of er kan geen verschil worden aangetoond. ${ }^{13}$ Wel bleek de aard van de aanvullingen te veranderen met het expertiseniveau: ouderejaars studenten zouden meer passende informatie voor een casus aanvullen, terwijl het bij jongerejaars vaak ging om informatie uit eerdere casus. ${ }^{13}$ Het is onduidelijk wanneer de verschillende stappen in de expertiseontwikkeling worden doorlopen en of effecten daarvan reeds herkenbaar zijn binnen het basiscurriculum van de opleiding geneeskunde. 
Datgene wat studenten waarnemen in een gesprek is moeilijk los te zien van hun communicatievaardigheden. Uit de literatuur blijkt dat ouderejaars studenten slechter gaan communiceren, als ze geen training krijgen. ${ }^{14}$ Dit kan worden veroorzaakt doordat studenten aan het begin van hun studie nog niet gehinderd worden door medische kennis en onbevangen kunnen luisteren naar alle aspecten van het verhaal van de patiënt. Verder in de studie wordt het steeds belangrijker om tijdens een consult ook zoveel mogelijk medische feiten boven tafel te krijgen en ontstaat er een competitie tussen het verhaal van de patiënt en de zich opdringende medische kennis. Dat relevante medische gegevens daarbij voorrang krijgen boven informatie die voor de diagnose minder van belang is (bijvoorbeeld emotionele aspecten), wordt regelmatig geuit door ouderejaars studenten en bemerkt door de auteurs tijdens het communicatievaardighedenonderwijs.

\section{Context van de studie}

Aan de Universiteit Maastricht (UM) worden communicatievaardigheden getraind in een longitudinaal programma (MPO: Medisch Praktisch Onderwijs) als onderdeel van de vaardigheidstrainingen binnen het Skillslab, geïntegreerd in de eerste vier jaren van het curriculum. Studenten oefenen vanaf het eerste blok in het eerste jaar meteen met volledige consulten in simulatiepatiënten-contacten. De consulten gaan inhoudelijk over onderwerpen die op dat moment worden bestudeerd in het kader van de blokthematiek. De contacten worden op video vastgelegd en op een later tijdstip bekeken en besproken door een aantal jaargenoten en één of twee begeleiders (zie van Dalen et al. voor een volledige omschrijving van het $\mathrm{MPO}^{15}$ ).
In eerder onderzoek is aangetoond dat het niveau van communicatievaardigheden van studenten in dit curriculum blijft toenemen gedurende de eerste vier jaren van de opleiding. ${ }^{16-17}$

\section{Vraagstelling}

Deze tegenstrijdigheden en het ontbreken van consensus in de literatuur zijn de aanleiding geweest om na te gaan wat studenten in het basiscurriculum geneeskunde daadwerkelijk horen tijdens een gesprek met een patiënt. We nemen aan dat de expertise gedurende het basiscurriculum ontwikkeling vertoont. Toename in expertise operationaliseren we als 'toename van diagnostische kennis'. Als zou blijken dat gevorderde studenten inderdaad bepaalde informatie van de patiënt niet waarnemen, dus als er daadwerkelijk sprake is van selectieve perceptie, dan zouden we hierop behoren in te grijpen tijdens het communicatievaardigheden onderwijs.

Zodra je iemand vraagt wat hij gehoord heeft, test je echter meteen zijn geheugen. Daarom hebben we de tijd tussen perceptie en recall zo kort mogelijk gehouden, zodat eventuele tussenprocessen te verwaarlozen zijn. De literatuur over recall op verschillende expertiseniveaus gaf ons weinig houvast over de te verwachten resultaten, niet alleen vanwege de grote diversiteit in methodiek en resultaten, maar ook vanwege het onbekende verloop van expertiseontwikkeling binnen het basiscurriculum.

De vraagstelling in dit onderzoek was: "Komt een toename in expertise binnen het basiscurriculum tot uiting in een toenemend selectieve perceptie van informatie tijdens een patiëntencontact?"

We hebben onderscheid gemaakt tussen recall van typische en atypische klachten en de volgende hypothesen opgesteld: 
- Studenten met meer diagnostische kennis geven minder atypische klachten weer dan studenten uit lagere studiejaren.

- Studenten met meer diagnostische kennis geven meer typische klachten weer bij een diagnose dan studenten uit lagere studiejaren, ook als deze niet door de patiënt worden geuit.

\section{Methode}

\section{Populatie}

Eerste- tot en met vierdejaars studenten geneeskunde aan de UM werden benaderd via oproepen tijdens onderwijsbijeenkomsten en brieven in hun postvakjes. Van de totaal circa 1000 studenten reageerden er 159 positief. Tijdens de uitvoering van het onderzoek bleken veertien studenten verhinderd. Van één student gingen de data door een technische storing verloren. Voor de verdeling van de uiteindelijk 144 studenten over de vier jaren: zie tabel 1. De representativiteit van de deelnemende studenten ten opzichte van hun jaargroep werd getoetst door resultaten voor een kennistoets (Voortgangstoets) te vergelijken. Slechts de groep deelnemers uit jaar vier bleken een significant hogere score te hebben op deze toets dan hun jaargenoten. Van de mensen in het onderzoek was $75 \%$ vrouw, een iets hoger percentage dan in de hele opleiding. Alle studenten ontvingen een kleine financiële vergoeding voor hun deelname.

Tabel 1. Verdeling deelnemers.

\begin{tabular}{lcccc}
\hline Jaargroep & $\mathbf{1}$ & $\mathbf{2}$ & $\mathbf{3}$ & $\mathbf{4}$ \\
\hline Deelnemers & 36 & 36 & 39 & 33 \\
\hline
\end{tabular}

\section{Materialen}

Voor dit onderzoek werden drie casus uit het reguliere communicatievaardigheden onderwijs aangepast. Er werd gekozen voor de onderwerpen 'pijn op de borst' (angina pectoris), 'ziek' (pneumonie) en 'pijn in de arm' (cervicaal radiculair syndroom), omdat deze casus aan bod komen in de loop van de eerste vier studiejaren. Elke casus werd zodanig bewerkt dat de specifieke rol niet herkenbaar was voor de studenten. Voor elke rol werden drie categorieën klachten onderscheiden: A: typische voor de betreffende diagnose die de simulatiepatiënt moest noemen, B: typische klachten voor de diagnose die echter bij deze patiënt niet voorkwamen en C: atypische klachten die deze patiënt wel rapporteerde. Deze classificatie kwam tot stand op basis van literatuur over elke aandoening aangevuld met een onafhankelijke beoordeling door drie huisartsen (bijlage 1). We hebben ervoor gekozen de casus te presenteren in de vorm van een videofragment, als compromis tussen realiteit (een echt gesprek voeren) en methodologische uitvoerbaarheid (wat in eerdere onderzoeken vaak doorslaggevend is geweest, bijvoorbeeld bij het gebruik van geschreven casus). Drie ervaren simulatiepatiënten werden getraind. De casus werden als consulten opgenomen op video, in arts-perspectief: de camera werd over de schouder van de arts op de patiënt gericht. Hierdoor kon de student zich het beste identificeren met de arts. De artsenrol werd gespeeld door een ervaren huisarts, die op de hoogte was van de informatie die wel/niet aan bod mocht komen. Hij kreeg de instructie niet expliciet te vragen naar klachten uit categorie B en geen samenvattingen te geven.

In samenwerking met de afdeling Medische Informatica van de UM werd een 
computerprogramma ontwikkeld, waarmee studenten individueel de drie filmpjes konden bekijken. De student kon de klachten die hij zich herinnerde direct na het filmpje in het programma invoeren, evenals de hulpvraag en de diagnose. Bij "diagnose" kon ook de optie "weet ik niet" worden ingevuld. Bij het invoeren van de hulpvraag bood het programma een keuze uit acht veel voorkomende redenen van een patiënt om een arts te zien. De studenten konden hieruit een keuze maken óf desgewenst een eigen omschrijving van de hulpvraag invoeren. Om de realiteit zoveel mogelijk te benaderen, gaf het programma géén mogelijkheid om de filmpjes terug te spoelen of vaker te bekijken.

\section{Procedure}

Er werden sessies georganiseerd voor maximaal twintig studenten. Studenten kregen een standaard instructie om elk filmpje goed te bekijken, zich in te leven in de artsenrol en achteraf zo veel mogelijk klachten te rapporteren die de patiënt had geuit. Ook werd hen geïnstrueerd de hulpvraag van de patiënt en de diagnose in te voeren. Om een eventueel volgordeeffect uit te sluiten werden de casus in willekeurige volgorde aangeboden. Direct na elk consult moest elke student op zijn eigen computer de informatie invullen die hij van de betreffende patiënt had gehoord. Daarna kon hij pas verder met het volgende stukje film.

\section{Analyse}

$\mathrm{Na}$ alle sessies werden alle ingevoerde klachten ingedeeld in eerdergenoemde categorieën. Omdat er ook klachten waren ingevoerd die tevoren niet in één van de categorieën waren ondergebracht, werd er nog een restcategorie toegevoegd (D). Om te controleren of de diagnostische kennis van de studenten in opeenvolgende jaren daadwerkelijk toeneemt, werden ook de ingevoerde diagnoses gecategoriseerd. Voor elke casus kon de diagnose vallen onder de categorieën: "juist”, "onjuist" of "geen diagnose ingevuld". Ook deze indeling werd beoordeeld door een huisarts (bijlage 2).

Eventuele verschillen tussen de jaren in de gemiddelde aantallen gerapporteerde klachten per categorie, werden met een one-way ANOVA getoetst. Ook verschillen per jaar tussen de gemiddelde aantallen diagnoses in elke categorie werden met one-way ANOVA berekend. In beide gevallen werd de post-hoc correctie volgens Bonferroni toegepast. Een significantieniveau van 0.01 werd aangehouden.

\section{Resultaten}

\section{Klachten}

Door alle studenten gezamenlijk werden in totaal 2929 klachten ingevoerd. Per casus rapporteerde elke student gemiddeld iets minder dan vijf klachten, terwijl de vooraf gemaakte indeling negen tot twaalf klachten per casus omvatte die aan bod kwamen tijdens het gesprek (categorieën $A$ en $C$, bijlage 1 ). De invoer van de drie casus werd opgeteld om zo algemene conclusies te kunnen trekken over recall. Dit was mogelijk omdat de data bij de verschillende rollen sterke overeenkomst vertoonden. Verschillen werden significant bevonden als $\mathrm{p}=0.01$. Onderstaande tabel laat voor elk studiejaar de gemiddelde aantallen gerapporteerde klachten in een categorie zien voor de drie casus samen, evenals de belangrijkste parameters van de uitgevoerde ANOVA.

Klachten uit categorie B werden vrijwel niet gerapporteerd (slechts vijf keer op het totaal van 2929 klachten), de studenten herinnerden zich dus geen klachten die niet genoemd waren. Ook de invoer van restklachten (categorie D) was beperkt. 
Tabel 2. Gemiddeld aantal klachten per categorie over het totaal van drie casus.

\begin{tabular}{lccccccc}
\hline Jaar & $\mathbf{1}$ & $\mathbf{2}$ & $\mathbf{3}$ & $\mathbf{4}$ & $\mathbf{F}$ & $\mathbf{d f}$ & Sign. \\
\hline A & 6.56 & 6.64 & 7.41 & 7.27 & 1.340 & 143 & 0.264 \\
B & 0.03 & 0.03 & 0.05 & 0.03 & 0.144 & 143 & 0.934 \\
C & 6.42 & 6.81 & 6.46 & 6.30 & 0.195 & 143 & 0.900 \\
D & 1.00 & 0.67 & 0.85 & 0.82 & 0.465 & 143 & 0.707 \\
\hline A= Typische klachten, genoemd & \multicolumn{7}{l}{ C= Atypische klachten, genoemd } \\
B= Typische klachten, niet genoemd & D= Overig
\end{tabular}

Tabel 3. Gemiddeld aantal diagnoses per categorie over het totaal van drie casus.

\begin{tabular}{lccccccc}
\hline Jaar & $\mathbf{1}$ & $\mathbf{2}$ & $\mathbf{3}$ & $\mathbf{4}$ & $\mathbf{F}$ & df & Sign. \\
\hline Juist & 0.47 & 0.64 & 2.00 & 1.79 & 63.740 & 143 & 0.000 \\
Onjuist & 1.00 & 1.47 & 0.92 & 1.12 & 3.922 & 143 & 0.010 \\
$?$ & 1.44 & 0.83 & 0.08 & 0.09 & 38.088 & 143 & 0.000 \\
\hline
\end{tabular}

Met ANOVA werden tussen geen van de jaren en geen van de categorieën verschillen aangetoond in de recall van klachten.

\section{Diagnose}

De gerapporteerde diagnoses gaven een minder eenduidig beeld. In tabel 3 is voor elk studiejaar het gemiddeld aantal diagnoses voor de drie casus samen in elke categorie gegeven en tevens de belangrijkste waarden van de ANOVA.

Het aantal juiste diagnoses nam weliswaar toe met opklimmend studiejaar, maar er zijn twee groepen: jaar 1 en 2 aan de ene kant met slechts een beperkt aantal juiste diagnoses, aan de andere kant jaar 3 en 4 met een hogere score. Post-hoc analyse bevestigde deze verschillen. Het aantal onjuiste diagnoses vertoonde géén tegengestelde relatie: het aantal fouten per studiejaar toonde alleen een klein significant verschil tussen jaar 2 enerzijds en jaar 1 en 3 anderzijds, waarbij de tweedejaars de hogere score hadden. In de hogere jaren wordt weinig gekozen om "geen diagnose" in te vullen. ANOVA laat een significante afname zien tussen de op- eenvolgende jaren 1, 2 en 3. Tussen de jaren 3 en 4 blijft deze categorie constant.

\section{Discussie}

De eerste hypothese (studenten met meer diagnostische kennis nemen atypische klachten minder goed op dan studenten uit lagere studiejaren) wordt verworpen, aangezien er geen verschil werd aangetoond in de herinnering voor atypische klachten door de vier groepen studenten. Aangezien er vrijwel nooit klachten werden gerapporteerd die niet door de patiënten werden genoemd (categorie B) en de recall van typisch genoemde klachten (categorie A) niet verschilde tussen de jaren, wordt ook de tweede hypothese (studenten met meer diagnostische kennis horen vaker typische klachten bij een diagnose, ook als deze niet door de patiënt worden geuit) verworpen.

Voor het ontbreken van verschillen kunnen een aantal verklaringen worden gegeven. De meest voor de hand liggende verklaring is dat er ook daadwerkelijk geen verschil in perceptie ís; de (getrainde) studenten blijven onbevangen luisteren naar 
het verhaal van een patiënt. Maar een aantal andere factoren hebben waarschijnlijk ook een rol gespeeld. De studenten kregen voorafgaand aan het bekijken van de videofragmenten een uitleg, waarbij het onvermijdelijk was om aan te geven dat later naar de klachten van de patiënt werd gevraagd (i.v.m. de uitleg van het computerprogramma). Er werd óók van de deelnemers gevraagd om zich zo goed mogelijk in te leven in het diagnostisch proces. Toch is het denkbaar dat het feit dat de studenten, meer dan in een echt consult, konden focussen op de klachten van de patiënt de verschillen tussen de jaren verdoezelt. Hoewel het bekijken van een film realistischer is dan het lezen van papieren casus, zijn er ook aan deze aanbiedingsvorm beperkingen. Een ander belangrijk punt is dat het aantal gerapporteerde klachten in categorie B (typische klachten, niet genoemd) wel heel minimaal is: het optreden van een bodemeffect is niet geheel uit te sluiten. Tenslotte is het verschil in expertiseniveau tussen de vier jaargroepen wellicht niet groot genoeg om überhaupt effecten op recall aan te kunnen tonen.

Bij de testresultaten van de controlemeting (neemt diagnostische kennis voor deze casus echt toe?) vallen een aantal dingen op. Ouderejaars studenten geven inderdaad meer goede diagnoses, maar deze toename gaat niet geleidelijk: er bestaan twee groepen. Studenten uit de jaren 1 en 2 aan de ene kant hebben significant minder diagnoses goed dan de derde- en vierdejaars aan de andere kant. Oorzaak van dit fenomeen is waarschijnlijk dat de studenten van het oude curriculum geneeskunde aan de UM in jaar drie pathologie gaan bestuderen en de (typische) ziektebeelden uit onze casus (te) makkelijk herkennen.

Heel opvallend bij deze meting was het vrijwel constante aantal foute diagnoses dat door alle studenten werd gerapporteerd, gepaard met een afname van de optie "ik weet geen diagnose" in de hogere jaren. Dit betekent dat als de diagnose niet helemaal duidelijk is, de studenten uit de eerste jaren dit eerlijk toegeven (door de optie "weet ik niet" in te vullen), terwijl de studenten met meer (maar blijkbaar niet voldoende) medische kennis eerder een onjuiste diagnose invoeren. Een verklaring hiervoor kan zijn dat de ouderejaars studenten (door een grotere ervaring met toetsing) meer gewend zijn een gokje te wagen als ze een antwoord niet weten. Dit 'gok-gedrag' kan in het geval van dit onderzoek nog versterkt worden door het ontbreken van consequenties voor de student bij het geven van een fout antwoord. Een mogelijk alternatief voor deze verklaring is dat de ouderejaars studenten hun kennis overschatten. Dit zou een zeer onwenselijk fenomeen zijn, met name voor de vierdejaars studenten. Zij komen immers zeer snel in een klinische setting terecht, waar een foute diagnose grote gevolgen kan hebben. Verder onderzoek is nodig om na te gaan of deze vorm van overschatting een algemeen voorkomend verschijnsel is.

Ook andere beperkingen van dit onderzoek kunnen met vervolgstudies worden ondervangen. Studenten echt zelf een consult laten voeren zorgt methodologisch voor meer storende factoren, maar kan zeker de moeite waard zijn gezien de eventuele nadelen van het focussen op recall. Daarnaast zou ook het gebruik van moeilijkere casus wellicht een ander beeld geven. Tenslotte zouden co-assistenten kunnen worden benaderd, omdat daarmee een groter verschil in expertiseontwikkeling wordt gecreëerd. Op basis van het huidige onderzoek lijkt selectieve perceptie van patiënteninformatie echter in de eerste vier studiejaren nog niet op te treden. Ingrijpen tijdens het communicatievaardighedenonderwijs lijkt hierdoor niet nodig. 


\section{Literatuur}

1. Groot AD de. Het denken van den schaker. Den Haag: North Holland; 1946.

2. Chase WG, Simon HA. Perception in chess. Cognit Psychol 1973;4:55-81.

3. Coughlin LD, Patel VL. Processing of critical information by physicians and medical students. J Med Educ 1987;62:818-28.

4. Norman GR, Jacoby LL, Feightner JW, Cambell EJM. Clinical experience and the structure of memory. Paper presented at the 18th Conference on research in Medical Education 1979, Washington DC.

5. Norman GR, Brooks LR, Allen SW. Recall by expert medical practitioners and novices as a record of processing attention. J Exp Psychol Learn Mem Cogn 1989;15(6):1166-74.

6. Schmidt HG, Norman GR, Boshuizen HPA. Cognitive perspective on medical expertise: theory and implications. Acad Med 1990;65(10): 611-21.

7. Schmidt HG, Boshuizen HPA. On acquiring expertise in medicine. Educational Psychology 1993;5(3):205-21.

8. Custers EJFM, Regehr G, Norman GR. Mental representations of medical diagnostic knowledge; a review. Acad Med 1996;71(10):S55-S61.

9. Norman GR, Regehr G. Cognitieve psychologie: huidige ontwikkelingen en hun implicaties voor het medisch onderwijs. Bulletin Medisch Onderwijs 1996;15:98-113.

10. Custers EJFM, Boshuizen HPA, Schmidt HG. The role of illness scripts in the development of medical diagnostic expertise: results from an interview study. Cognition and Instruction 1998;16(4):367-98.

11. Patell VL, Groen GJ, Frederiksen CH. Differences between medical students and doctors in memory for clinical cases. Med Educ 1986;20:3-9.
12. Eva KW, Norman GR, Neville AJ, Wood TJ, Brooks LR. Expert-novice differences in memory: a reformulation. Teach Learn Med 2002;14(4):257-63.

13. Claessen HFA, Boshuizen HPA. Recall of medical information by students and doctors. Med Educ 1985;19:61-7.

14. Pfeiffer C, Madray H, Ardolino A, Willms J. The rise and fall of students' skills in obtaining a medical history. Med Educ 1998;32:283-8.

15. Dalen J van, Bartholomeus P, Kerkhofs E, Lulofs R, Thiel J van, Rethans J-J, Scherpbier AJJA, Vleuten CPM van der. Teaching and assessing communication skills in Maastricht: the first twenty years. Med Teach 2001;23:245-51.

16. Evans BJ, Coman CJ, Goss B. Consulting skills training and medical students' interviewing efficiency. Med Educ 1996:30:121-8.

17. Dalen J van, Kerkhofs E, Knippenberg-van den Berg BW van, Hout HA van den, Scherpbier AJJA, Vleuten CPM van der. Longitudinal and concentrated communication skills programmes compared: two Dutch medical schools compared. Adv Health Sci Educ 2002;7:29-40.

\section{De auteurs:}

Drs. M.M.L. van den Hove, student-assistent Skillslab, Faculteit der Geneeskunde.

Dr. J. van Dalen, Skillslab, Faculteit der Geneeskunde.

Dr. J-J. Rethans, Skillslab, Faculteit der Geneeskunde.

Dr. E.H.B.M. Gronenschild, afdeling Medische Informatica.

Dhr. S. Roos, afdeling Medische Informatica.

Allen zijn verbonden aan de Universiteit Maastricht.

\section{Correspondentieadres:}

Dr. J. van Dalen, Universiteit Maastricht, Skillslab FdG, Postbus 616, 6200 MD Maastricht, tel: 043-3881793, MML.vandenhove@student.unimaas.nl.

\section{Summary}

Introduction: Recall of patient information by medical experts and novices has been studied extensively, but conflicting results have been obtained. This study evaluates the recall of patients' complaints by medical students at different stages in their medical training (i.e. with different levels of diagnostic knowledge). Our hypotheses were:

- Students who have more diagnostic knowledge reproduce fewer atypical complaints than students with less diagnostic knowledge.

- Students who have more diagnostic knowledge more often reproduce typical complaints even if the patient does not mention them.

Method: Three simulated patient encounters were videotaped and watched by medical students divided in groups according to their year of training from Year 1-4. They were asked to enter on the computer as many complaints as they could remember as well as the diagnosis they considered most likely immediately after watching the tape. The complaints listed were classified into four categories: Typical-atypical and mentioned-not-mentioned. The input was processed and differences between the student groups were analysed using ANOVA.

Results: No significant differences were found regarding the recall of complaints. In cases where there was doubt, students with more diagnostic knowledge made proportionally more errors in the likely diagnoses, possibly because they overestimated their diagnostic knowledge.

Conclusion: Increase in diagnostic knowledge during the first four years in medical school does not seem to influence the perception and recall of complaints observed on videotape. Further study is recommended to determine the effect of increasing expertise on recall in later years, as well as on the possible overestimation of diagnostic knowledge. (Van 
den Hove MML, Van Dalen J, Rethans J-J, Gronenschild EHBM, Roos S. Selective perception in the medical interview: the effect of diagnostic knowledge on the perception of complaints in patient encounters. Dutch Journal of Medical Education 2004;23(3):133-142.)

Bijlage 1. Indeling klachten.

\begin{tabular}{|c|c|c|c|}
\hline Patiënt/rol & A & B & C \\
\hline Pijn op de borst & $\begin{array}{l}\text { Pijn op de borst } \\
\text { Snoerend/drukkend gevoel } \\
\text { Benauwdheid } \\
\text { Angstig } \\
\text { Al eerder gehad } \\
\text { Pijn bij inspanning }\end{array}$ & Uitstraling & $\begin{array}{l}\text { Pijn in de bovenbuik } \\
\text { Dorst } \\
\text { Hartkloppingen } \\
\text { Moe }\end{array}$ \\
\hline Ziek & $\begin{array}{l}\text { Beroerd voelen/malaise } \\
\text { Rillerig } \\
\text { Vastzittende hoest } \\
\text { Pijn bij hoesten/ademen } \\
\text { Moe, tot niets in staat zijn } \\
\text { Klachten terug na verbetering }\end{array}$ & $\begin{array}{l}\text { Sputum } \\
\text { Koorts }\end{array}$ & $\begin{array}{l}\text { Oorpijn } \\
\text { Schor/hees } \\
\text { Duizelig } \\
\text { Spierpijn } \\
\text { Gehoorverlies } \\
\text { hoofdpijn }\end{array}$ \\
\hline Pijn in de arm & $\begin{array}{l}\text { Stekende pijn onderarm } \\
\text { Pijn bij kijken omhoog \& rechts } \\
\text { Erger bij hoesten, niezen, persen } \\
\text { Uitstraling vanuit nek } \\
\text { Zwaar gevoel arm }\end{array}$ & $\begin{array}{l}\text { Tintelingen in vingers } \\
\text { Krachtsverlies }\end{array}$ & $\begin{array}{l}\text { Pijn in rug } \\
\text { Warme schouder } \\
\text { Koude vingers } \\
\text { Slapeloosheid }\end{array}$ \\
\hline
\end{tabular}

$\mathrm{A}=$ Typische klachten, genoemd; $\mathrm{B}=$ Typische klachten, niet genoemd; $C=$ Atypische klachten, genoemd; $\mathrm{D}=$ Overig

Bijlage 2. Indeling diagnose.

\begin{tabular}{lll}
\hline Patiënt/rol & Juiste diagnose & Onjuiste diagnose \\
\hline Pijn op de borst & Angina pectoris & Verkramping tussenribspieren \\
& Angina & Infarct \\
& Vernauwing kransslagaders & Overbelasting \\
& Slechte conditie \\
& Hyperventilatie \\
& 'Hart' \\
& 'lets met hart' \\
& Hartritmestoornis \\
& Hartfalen \\
& Atriumfibrilleren \\
& 'Coronair' \\
& Cardiogene shock \\
& Géén hartafwijking \\
& Pneumonie & Griep/influenza \\
Bacteriële luchtweginfectie & Infectie \\
Griep met bacteriële superinfectie & Vocht in oor \\
& Oorontsteking \\
& Beginnende verkoudheid \\
& & Virusinfectie
\end{tabular}


Vervolg Bijlage 2.

\begin{tabular}{lll}
\hline Patiënt/rol & Juiste diagnose & Onjuiste diagnose \\
\hline Pijn in de arm & HNP & 'Plexus brachialis' \\
& Hernia & Nekklachten \\
& Beklemming zenuw & Rugklachten \\
& Compressie plexus brachialis & Embolie in bloedvat bovenarm \\
& Cervicaal radiculair syndroom & 'Verkouden schouder' \\
& Thoracic outlet syndroom \\
& Beklemde zenuw onderrug \\
& Reuma \\
& Ontsteking zenuwbanen \\
& lets met een zenuw \\
& 'Zenuw' \\
& Ontsteking in schouder \\
& Sensibiliteitsstoornis \\
& Epicondylitis Medialis \\
& Beklemde arterie \\
& Trauma \\
& 'Zenuwstelsel' \\
& Afknelling door maligniteit/ontsteking \\
\hline
\end{tabular}

